

\title{
A MINI-CAVITY PROBE REACTOR
}

by Robert E. Hyland

Lewis Research Center

Cleveland, Ohio

TECHNICAL PAPER proposed for presentation at

Uranium Plasma Conference sponsored by the American Institute of Aeronautics and Astronautics Atlanta, Georgia, November 15-17, 1971 
Robert I. Hyland

Lewis Research Center

National Aeronautics and Space Aoministration Cleveland, Ohio

\section{Abstract}

The mini-cavity reactor is a rocket engine concept which combines the high specific impulse from a central gaseous Iueled cavity $(0.6 \mathrm{~m}$ diam) and NERVA type fuel elements in a driver region that is externa? to a moderator-renlector zone to produce a compact light weight reactor. The overal1 dimension including a pressure vessel that if is located outside of the spherical reactor is (1) approximately $1.21 \mathrm{~m}$ in diameter.

Specific impulses up to 2000 sec are obtainable for 220 to $890 \mathrm{~N}$ of thrust with pressures

less than 1000 atm. Powerplant weights including a radiator for disposing of the power in the driver region are between 4600 and $32000 \mathrm{~kg}$ - less than payloads of the shuttle.

This reactor could also be used as a test reactor for gas-core, MHD, breeding and materials research.

\section{Introduction}

Lately, there has been a re-emphasis on unmanned space missions both for the near future and the distant future (i.e. Grand Tour). Advanced propulsion concepts are the result of an attempt to obtain high specific impulse (pound of thrust per pownd of propellant hlow per second) with high thrust-to-power-plant-welght. These characteristies have the effect of reducing trip times and/or increasing payload capabilities. It is quite possible that reduction of trip times will become an important requirement of future deep space missions. If so, there will be a need for high impulse without overly sacrificing thrust-to-weight ratios.

Chemical rockets are limited to $I_{S p}$ in the 400 sec range and solid fueled nuclear rockets are limited to approximately $900 \mathrm{sec}$. I ( 1 imited by materials temperature). Both electricl, 2 and gascore rockets ${ }^{3}$ have or are capable of providing Impulses in the order of thousands of seconds. Flectric thrusters suffer from low thrust-to-weight ratios, while the gas-core suffers from large size and weight.

The purpose of this paper is to present a concept which combines the impulse from the gas-core with the compactness and low weight of a NERVA type reactor. This concept, presently nicknamed the mini-cavity, has a central cavity region used for propulsion power, surrounded by a moderator region which thermalizes neutrons from a driver region located outside of the moderator region but inside of a pressure vessel. The driver region can use fuel elements developed under the INERVA program because an inert gas 4 can be used in place of hydrogen for cooling. This combination has the potential of yielding a compact, easily controlled reartor, capable of several thousand seconds of Isp. In addition, the concept may provide a method for developing the gas-core reactor (both open and closed cycle) and also be capable of provicine high outlet gas temperatures where Mis becomes very efficient.

\section{Symbols}

$A_{R}$ Rosseland mean absorption coefticlent, $m^{-1}$

DC cavity diameter, $m$

DF . fuel diameter, $\mathrm{m}$

E exponential integrals

F . thrust, N

H: enthalpy, J/kg

$I_{\text {Sp }}$ specific inpulse, sec

K . thermal conductivity, W/m - I

$M_{\mathrm{F}}$. mass of fuel, $\mathrm{kg}$

(9)

cavity pressure, atm

geat flux, $W / m^{2}$

R radius of reactor, $\mathrm{n}$, $\mathrm{cm}$

s

radial distance in eavity, om

allowable stress, $N / \mathrm{m}^{2}$

T. temperature, $\mathrm{K}$

t thickness of pressure vessel, cm

$V_{F}$ volume fraction of fuel, uranium to cavity

v. velocity, $\mathrm{m} / \mathrm{sec}$

P. density, $\mathrm{gm} / \mathrm{cc}$

o Stefan-Boltzmann constant, $W / n^{2}-n^{4}$

T. optical depth

\section{Analysis}

The analysis for this reactor concept is divided into three areas: nuclear, propulsior, and weight. A more detailed nuelear analysis is reported in Ref. 6. The propulsion and welicht analysis are discussed in this report. The weight analysis includes weights of the reactor, pressure shel1, pumps and radiator.

\section{Nuclear Analysis}

The mini-cavity concept is a combination of two reactor types, a sas core surrounded by a solid fueled reactor. To keep this combination smalli and 1ight weight, a diameter less thon $200 \mathrm{~cm}$ was set as the goal. Experimental cesults, 7, 8 indicate cavity diameters of 25 to 45 cn can produce 
relatively large, stable flow patterns for the low velocity, heavier central gas regions. Based on optimization studies, ${ }^{6}$ and to keep within the goal of $200 \mathrm{~cm}$ diameter, a cavity diameter of $60.96 \mathrm{~cm}$ (2 ft) was selected for the analysis. The remaining reactor regions composed of reflector and driver (fuel) elements were variable but an overall diameter of $121.92 \mathrm{~cm}$ ( $4 \mathrm{ft}$ ) as shown in Fig. I was maintained.

The uranium fuel region in the cavity was held to a radius of $2 I \mathrm{~cm}\left(\mathrm{DF}_{\mathrm{F}} \mathrm{C}=0.7\right)$. The uranium density was varied to obtain the effect on reactivity and obtain values over the range of chamber pressures (200 to $1000 \mathrm{~atm}$ ). The reflector region (beryllium oxide) between the cavity and the driver fuel zone as shown in Fig. 2 was varied as reported in Ref. 6. An optimum thickness of $15 \mathrm{~cm}$, based on maximum power fraction in the cavity was obtained.

The driver region was varied in several ways. The region was either considered as one region or was split into two equal thickness regions with moderator ( $\mathrm{BeO})$ between. The fuel density for the split regions was either uniform or was varied between each region. And the location with respect to the cavity was varied. The results of these variations as reported in Ref. 6 indicate that a single fuel zone with uniform fuel produced the highest ratio of power in cavity to power in driver region.

The outermost region of the mini-cavity considered in the nuclear calculations was the pressure vessel. Because the driver region is located. near the outer periphery of the reactor there is considerable fast neutron leakage. By adding a thick fast reflector such as the pressure vessel, the reactivity is enhanced by the reflection of the fast neutrons back into the reactor thus allowing a reduction of fuel density in the driver region.

The nuclear analysis performed on the calculational model shown in Fig. ${ }^{2}$, was handled by transport theory using TDSN. 9 "The analysis used 19 energy groups, with 7 in the thermal range, and a.lowed for upscattering into 7 energy levels above and downscattering into 8 levels below. An $\mathrm{S}_{4}$ anguiar approximation was used with a onedimensional spherical analysis.

A11 modifications to the geometry or materials was done on the basis of increasing the power in the cavity relative to the power in the driver region. As reported in Ref. 6, the use of uranium isotope 233 greatly increased this ratio of power. This increase in power was due to the decrease in uranium density in the driver region for a given amount of fuel in the cavity. The decrease in fuel density also allows the flux in the moderator to increase which also adds to the relative power in the cavity fuel. The results presented in this report are predominately based on the use of $233 \mathrm{U}$ as the fuel in both driver and cavity. A comparison with $235 \mathrm{U}$ isotope is presented as part of the discussion.

\section{Propulsion Analysis}

The propulsion capability of the mini-cavity reactor is obtained by passing hydrogen through the cavity walls (predominantly tangent to wall), around a central fuel region where the hydrogen (seeded) picks up heat via radiation absorption, and out through a nozzle for expansion and thrust.

In the cavity, attainment of fuel temperatures sufficiently high to cause vaporization of solid uranium particles depends on back radiation from the surrounding seeded hydrogen. By assigning a limiting cavity wall temperature (1523 K), a hydrogen propellant mass flow rate along with a seed mass fraction, the specific impulse and thrust level can be obtained for various pressure levels. The thrust and impulse are the maximum combination without exceeding the limitation set by the wall temperature and hydrogen flow rate. The heattransfer analysis used is discussed in detail. 10

The equation used in Ref. 10 to obtain the specific impulse from the hydrogen chamber enthalpy of the hydrogen is as follows,

$$
I_{\text {sp }}=\sqrt{1.497 \times 10^{-2} \mathrm{H}}
$$

This equation assumed an 85 percent energy efficiency in the exhaust nozzle expansion. From the enthalpy, the power required for heating the propellant can be obtained. Assuming this to be equivalent to the power produced in the fuel, the power of the cavity region is obtained. Since the neutronics calculation relates the power in the cavity to the power in the driver region, the total power of the reactor can be obtained.

After the thrust and specific impulse are known for a given cavity pressure, these values can be used in Eq. (1), 1 to obtain the amount of uranium fuel that would be contained in the cavity. This amount of fuel is then used in a nuclear calculation to obtain the additional fuel necessary in the driver region for an overall critical configuration.

$$
\mathrm{M}_{\mathrm{F}}=10.7 \frac{\mathrm{D}_{\mathrm{C}}^{3.28} \mathrm{P}^{0.723} \mathrm{v}_{\mathrm{F}} .092}{\mathrm{~F}^{0.277} \mathrm{I}_{\mathrm{SP}}^{0.277}}
$$

The remaining necessary information is the edge temperature of the fuel to determine whether or not the uranium will vaporize. The information is again obtained from the heat-transfer code used in Ref. 10 and is dependent on the back radiation from the propellant. The equations used to obtain the edge temperatures involved the energy equation

$$
\rho v \frac{\partial H}{\partial r}+\frac{1}{r^{2}} \frac{\partial\left(r^{2} q\right)}{\partial r}=0
$$

where $\mathrm{q}$ is the heat flux for the seeded propellant and is obtained from the following equation involving the temperature distribution from the wall to the edge of the fuel.

$$
\begin{aligned}
q= & -2 \sigma E_{3}(\tau)\left(T_{W}^{4}-T_{E D G E}^{4}\right) \\
& -\left\{K+\frac{8 \sigma T_{E D G E}}{A_{R}}\left[\frac{2}{3}-\tau E_{3}(\tau)+E_{4}(\tau)\right]\right\} \frac{d t}{d r}
\end{aligned}
$$

Where $E_{3}$ and $E_{4}$ are exponential integrals, $\sigma$ is the stefan-Boltzmann constant, $A_{R}$ the Rosseland mean absorption coefficient and $(\tau)$ is the optical depth and defined as 


$$
i^{t}=\int_{r_{1}}^{r_{2}} A_{R} d r
$$

Th this solution (referred to as the diffusion approximation), the results are more accurate with increasing optical depth. If the gas is optically thin, then the uranium "sees" the wall and the radiative heat transfer reverts to $\mathrm{T}^{4}$ type solution. For spherical shapes, the diffusion approximation according to Ret. 12 results in excellent agreement when optical thicknesses are seven or more times the mean optical path. The optical depth for cases discussed in this report are much larger (i.e. many mean optical paths).

In order to determine if the uranium at the outer edge of the fuel in the cavity is at a temperature high enough to be a gas, the following vapor pressure equation (obtainable from the results of Ref. 13) was applied, where P the chamber pressure is in atmospheres.

$$
\log (P)=5.998-\frac{25.742}{T}
$$

If the temperature, T, is less than the edge temperature not all of the fuel in that region is vaporized. The analysis to obtain the specific impulse considers both particle and gas species so the results are not changed if the uranium is not a. gas.

\section{Weight Analysis of Reector, Pressure Shell and Radiator}

The weight of the reactor is the sum of the weights of the noderator (Beo) and of the driver fuel elements. The main portion of the weight of the fuel elements is that of the graphite. The fuel element occupies 75 percent of the volume of the driver region. Fuel elements can be in the form of plates or pins or inverted matrix (i.e. holes in matrix). Since the fuel loadings run around $200 \mathrm{mg} / \mathrm{cc}$ of graphite compared to $1.6 \mathrm{gms} / \mathrm{cc}$ for graphite, the weight of the fuel element is considered to be that of the graphite. Since the reactor size was fixed for the analysis, the only significant variable 1 s the fuel loading in the driver region and the fuel in the cavity. These weights are less than $50 \mathrm{~kg}$ so the reactor weight for all practical purposes is a constant $2180 \mathrm{~kg}$ $(48001 \mathrm{~b})$.

The pressure shell which also acts as a fast neutron reflector is considered a separate item in the weight analysis. The minimum thickness is a function of the pressure level required for the cavity. However, since the pressure shell can act neutronically as a fast neutron reflector, it has an effect on the relative power (i.e. the greater the thickness, the lower the power needed in the driver region).

For this series of calculations, an amealed titanium alloy (TI, GAL, 4V) wes used because of its greater strength to weight ratio, high strength at high pressures, and established fabricability. An optimization study might provide a better or lower system weight but would involve a more detailled nuclear and weight aralyses. The thickness, $t$, for this study was obtained from the relationship of pressure, $P$, and stress $S$.

$$
t=\frac{P R}{2 S}
$$

The value used for $\mathrm{S}$, the allowable stress at $20^{\circ} \mathrm{C}$, for the titanium alloy was $4 .-13 \times 10^{\circ} \mathrm{l} / \mathrm{m}^{2}$ ( $60000 \mathrm{psi}$ ). The density used for the material. was $4.48 \mathrm{~g} / \mathrm{cc}\left(280 \mathrm{lb} / \mathrm{ft}^{3}\right)$.

Since the power levels and coolant rates are low, the pump weights are relatively small. Iquations such as those found in Ref. 14 result in very low weights, less than $9 \mathrm{~kg}(20.13)$ for $10 \mathrm{w}$ 11 ow rates. Even a factor of 10 lines or a purnp welght of $91 \mathrm{~kg}(200 \mathrm{lb})$ is an insigalficant weight for this analysis.

In this concept the enerey deposited in the driver region is rejected vila a realditor using an inert gas rather than diluting the propulsion high temperature gas from the cavity. Work reported in Ref. 15 on fin-tube radiators was $43 e d$ to establish the weight of the radiator per negawatt of power radiated, over the chamber pressure range used in this report. In that report meteroid damase was not taken into consideration. The temperature for the radiator was taken as $1000^{\circ} \mathrm{C}$, The radiator consisted of beryllium fins and TZM (nolybdenum a110y) tubes with the fins between tubes on a center-to-center basis. The resulting weight per megawatt of radiated power selected as a funct on of ehamber pressure is presented in ilis. 3. The weight of the radiator includes the header, tube block and fin chamber.

The total weight of the powerplant consists of the reactor weight, the pressure shell welicht, the pump weight and the radiator welght.

\section{Results and Discussions:}

The results presented and the 0.1 scussion with cover the power split between cavity and driver, specific impulse obtainable, fuel temperature in the cavity, powerplant weights, and possible applications or potential uses of the mini-cavlly reactor.

\section{Reactor Power Splits}

The amount of power produced i, the civity relative to the ariver region is very important in that total powerplant weight varies direetzy with cavity power fraction for a siven pressure and thrust level. The power produced in the cavity Ior this system is highly dependerl on the thermal flux in the moderator region between lle driver und the cavity. The ratio of power produced in the cavity to that of the driver is a function or boll the amount of fuel in the cavity and the anount in the driver. For a given amount of fluel th the cavity the lowest total fuel loading possible (criticalit) will result in the highest power split of the cavity to ariver. As a result of the work of Ref. 6 the use of $233 \mathrm{U}$ in the driver produced the highest power fractions for the cavily. In andition to the fuel in the criver, the chermal neutrons being returned to the caviuy are a lumetion of the moderator and its thickness. Mhis was optimized at approximately $15 \mathrm{~cm}$ for the BeO.

A typical plot of neutron flux (normel tred) is presented in Fig. 4. The plot is for entersy groups covering the high energy heutrons ( 1.4 to 
$0.5 \mathrm{MeV}$ ) and the thermal energy neutrons ( 0.08 to $0.025 \mathrm{eV})$. This plot compares flux levels obtained with both $233 \mathrm{U}$ and $235 \mathrm{U}$ in the driver fuel. The mass of uranium gas in the cavity can be increased (see eq. (1)) by the chamber pressure. This change in uranium mass in the cavity is plotted in Fig. 5(a) as a function of chamber pressure for various thrust levels. Associated with the chamber pressure and thrust level is the maximum $I_{\text {. The }}$ amount of allowable fuel increases with pressure for any given thrust but also increases as the thrust level decreases (i.e. lower temperatures in the gas). This increase of fuel in the cavity increases the power in the cavity relative to that produced in the driver region. This effect is presented in Fig. 5(b). The curves indicate that by using uranium isotope 233 cavity, power fractions of 0.20 or better can be obtained.

It should be noted here that as reported in Ref. 6, any increases in absorption in the reflector-moderator or driver fuels will reduce these power fractions. These reductions in power fraction will cause increases in powerplant weight. Values of only 0.06 were obtained in Ref. 5 where a pressure vessel was used between the cavity and moderator and $235 \mathrm{U}$ with Zircaloy 4 as the clad and structural material.

The power splits (cavity and driver) are presented in Table $I$ for a range of thrust and pressure levels. Also presented in the table is the fuel mass required in the driver region for criticality. For this range of thrust levels up to $890 \mathrm{~N}$ (200 lb) the power in the cavity was genera11y less than $10 \mathrm{MW}$ and the driver power less than $50 \mathrm{MW}$. This indicates fairly low total power levels will be required for propulsion. At the bottom of the table a comparison case using $235 \mathrm{U}$ as the fuel is presented. For the same amount of fuel in the cavity, an approximate 60 percent increase in power over that for U233 in the driver region is required. In addition the amount of fuel for criticality goes up from near $20 \mathrm{~kg}$ to $140 \mathrm{~kg}$. This shows that the use of $233 \mathrm{U}$ in the cavity as well as the driver is highly effective in reducing the fuel loading in the driver and thereby increasing the relative power in the cavity.

A calculation was performed ${ }^{6}$ in which only the cavity contained $233_{\mathrm{U}}(\mathrm{I} \mathrm{kg})$. For this case the reactor was critical with $103 \mathrm{~kg}$ of $235 \mathrm{U}$ in the driver region and the power split was 0.135.

\section{Specific Impulse}

As indicated in the section on analysis, the specific impulse is proportional to the square root of the enthalpy of the seeded hydrogen (seeded with $238 \mathrm{U}$ ). The enthalpy deposited in the gas (propellant) is a function of the pressure and temperature. In the calculations, the specific impulse for a given pressure could be increased slightly by the addition of U238 seed (more than required for radiation absorption). This increase is due to back radiation from the seeded hydrogen. A value of mass fraction of 0.25 was used to obtain the specific impulses presented in Fig. 6. For this concept as presented, a specific impulse of $2000 \mathrm{sec}$ is obtainable at a pressure of 1000 atm for a thrust level of $730 \mathrm{~N}(164 \mathrm{lb})$. All of the cases presented produce specific impulses greater than $1000 \mathrm{sec}$.

In the heat transfer calculations performed as per Ref. 10, a fuel temperature profile is obtained. The fuel edge temperatures (the lowest temperature of the fuel for the results in Fig. 6) are presented in Table 1 . As discussed earlier, these high temperatures are obtainable because the propellant gas is optically thick and there is back radiation to the fuel (uranium). There do exist some conditions in which a uranium particle would not evaporate. Without a complete analysis, it appears that all of the cases studied would produce a gaseous state, with the possible exception of the $222 \mathrm{~N}(50 \mathrm{lb} f)$ thrust values and some of the $200 \mathrm{~atm}$ pressure conditions.

\section{Powerplant Weight and Characteristics}

For the range of thrust 220 to $890 \mathrm{~N}$ (50 to $200 \mathrm{lbf}$ ) and the levels of specific impulse obtained, the propellant flow rates are very low. In most cases they are less than $0.0455 \mathrm{~kg} / \mathrm{sec}$. At predicted mass flow ratios of propellant-tofuel in the range of 100,7 the loss rate for uranium is less than $4.5 \times 10^{-4} \mathrm{~kg} / \mathrm{sec}$. At this rate the reactor could operate for over $10^{5} \mathrm{sec}$ before losing $45.0 \mathrm{~kg}$ of uranium.

The powerplant weight consists of the weights for the reactor, pressure shell, pumps and radiator. The reactor which is $121 \mathrm{~cm}$ ( $4 \mathrm{ft}$ ) in diameter weighs approximately $2180 \mathrm{~kg}(4800 \mathrm{lb})$, and the pumps are estimated at $91 \mathrm{~kg}(200 \mathrm{lb})$. Only the pressure shell and the radiator weights vary with pressure and power. As the pressure increases the specific impulse increases, and the allowable fuel in the cavity increases. With this the power split increases for the cavity requiring less power in the driver. This higher pressure requires an increase in pressure shell weight. The reduction of power in the ariver results in a smaller radiator at higher pressures, but because the pressure is increased the weight per megawatt of power increases. The result is an increase in radiator weight, and therefore an increase in powerplant weight, as shown in Table 2.

The powerplant weights are plotted in Fig. 7 as a function of thrust for three pressure levels. These plots are for reactors with $233 \mathrm{U}$ as the fuel both in the cavity and driver regions. For $445 \mathrm{~N}$ (100 Ib) of thrust, a comparison with using $235 \mathrm{U}$ is presented. Although there was a larger difference in the fuel required in the driver the engine weight penalty is only around 40 to 50 percent.

The powerplant weights obtained here ( 4500 to $32000 \mathrm{~kg}$ ) are less or comparable to the payloads considered in the shuttle program, so that a complete interplanetary rocket could be a payload for a shuttle rocket.

\section{Potential Uses of Mini-Cavity Reactor}

In reviewing the sizes, weights, temperatures and power levels, it becomes apparent that a small sized cavity could have applications other than as a propulsion device. Because of the small size and low power levels, a mini-core reactor could be used as a land-based test reactor for the gas-core 
reactor concept. Wall materials, injectors (propellant and fuel), control devices, nozzles, seeding and various measuring devices could be experimented on, under operating conditions.

The use of a gas-core reactor with MHD has been suggested in Refs. 16 to 18 . With a minicavity reactor, small MHD devices could be tested that could find direct application. Exhaust temperatures in the $4000^{\circ}$ to $5000^{\circ} \mathrm{C}\left(7650^{\circ}\right.$ to $\left.9500^{\circ} \mathrm{R}\right)$ range would be useful in the development of efficient MHD devices.

other applications could include new materials research and fission fuel breeding both in a blanket surrounding the reactor and as a hyproduct from the seeding.

\section{Conclusions}

A spherical reactor containing a central gaseous fueled cavity ( $0.6 \mathrm{~m}$ diam), surrounded by a Beo moderator $(15 \mathrm{~cm})$, followed by a driver region supplying the majority of the neutrons through the Beo moderator was analyzed to determine its potential respect for providing rocket propulsion at a low thrust level $(<900 \mathrm{~N})$ but high specific impulse (>1000 sec). This concept, called the mini-cavity, results in specific impulse well above that of a INERA type reactor, but less than that of a gas core reactor. The following results were obtained.

1. Cavity power levels less than $13 \mathrm{MW}$ coupled with driver power less than 60 MW can produce thrust levels of up to $890 \mathrm{~N}$ with specific impulse uo to $2000 \mathrm{sec}$.

2. Powerplants, including a radiator for dumping the power produced in the driver reactor, weigh between 4600 and $32000 \mathrm{~kg}$ for thrust levels between $220 \mathrm{~N}$ and $890 \mathrm{~N}$. These weights are less than payloads for the shuttle type rocket.

3. Because of the low propellant flow rates, the loss of uranium would be extremely low; approximately $50 \mathrm{~kg}$ over a period of $10^{5} \mathrm{sec}$ of firing.

4. In addition to having possibilities as a propulsion device, the mini-cavity could be used as a test reactor for the complete gas core, as a source for high temperature gas for testing MHD devices, and for use in materials research.

5. Using $233 \mathrm{U}$ as the fuel in both the cavity and the driver regions resulted in a substantial increase in relative power produced in the cavity compared to the use of $235 \mathrm{~J}$.

\section{References}

1. Terrisk, D. J. and Bartz, D. R., "Primary Electric Propulsion Technology-Toward Flight Programs for the Mid-1970s," Astronautics and Aeronautics, Vol. 6, No. 6, June 1968, pp. 4853.

2. Isley, W. C. and Mickelsen, W. R., "Electric Microthrusters Make It," Astronautics and Aeronautics, Vol. 6, No. 6, June 1968, pp. 5461.
3. Ragsdale, R. G. and Willis, E. A., Jr., "GasCore Rocket Reactors-A New Look, " Paper 71641, June 1971, A.TAA, New York, N.Y.

4. Gallagher, J. G. and Boman, 1. H., "The NERVA Technology Reactor for a Braytor Cycle Space Power Unit," Transactions of the American Nuclear Society, Vol. 12, No. 2, Not. 1969 , pp. $417-418$.

5. Arnat, S. A., "Test Facility for Small-Scale Fission-Heated Cavity Reactor Experinent, M. S. Thesis, 1970, Univ. Utah, Salt liake City. Utah.

6. Hyland, R. E., "Mini Gas-Core Propulsion Concept," Transactions of the American Nuclear Society, Vol. 14, No. 2, Oct. 1971. (To be published.

7. Bennett, J. C. and Johnson, B. Y., TExperimenta Study of one- and Two-Component Low-Thrbullence Confined Coaxial Flows," CR-1851, 1971, MASA, Washington, D.C.

8. Kunze, J. F., Lofthouse, J. H., Suckling, D. H., and Hyland, R. E., "Flow-Mixins, Reactivily Effects in the Gas Core Reactor," Iransactions of the American Nuclear Society, Vol. 11, No. 1, June 1971, p. 11 .

9. Barber, C. E., "A Fortran IV Two-Dimensione? Discrete Angular Segmentation Transport Program," TN D-3573, 1966, INASA, Cleveliand, Ohío.

10. Kascak, A. F., "Wall Cooling Limitation in Isp of Uranium Plasma Nuclear Rocket," Proposed Technical Memorandum, 1971, NASA, Cleveland, ohio.

11. Ragsdale, R. G., "Relationship Between Theine Parameters and the Fuel hass Contained in an Open-Cycle Gas-Core Reactor," Research on Uranium Plasmas and Their Technological Applications. SP-236, 1971, INASA, Washington, D. C., pp. $13-22$.

12. Siegel, R. and Howell, J. R., "Thermal Radiation Heat Transfer, Vol. III," SP-164, 1971, NASA, Washington, D.C.

13. Pattoret, A., Smoes, S., and Drowart, J., "Thermodynamic Studies by Mass Spectronetry," EUR-2458.f, 1965, Brussels Univ., Belgíum.

14. Bussard, R. W. and Delaver, R. D., Fundamentals of Nuclear Flight. McGraw-Hil1, New Yorl: 1965, p. 74.

15. Taylor, M. I., Whitmarsh, C. L., Jr., Sirochy, P. S., Jr., and Iwanczyk, L. C., "The OpenCyele Gas-Core Nuclear Rocket Englne - Some Engineering Considerations," 2nd Symoosium on Uranium Plasmas: Research and Amplications, Atlanta Georgia, Nov. 15-17, 1971

16. Rosa, R. J., Magnetohydrodynemic Iner: Con version, MeGraw-Hill, New York, 1968. 
17. Gritton, E. C. and Finkel, B., "The Feasibility of the Caseous-Core lifuclear Reactor for Electric-Forrer ieneration," RI-5721, June LOf9, Rand Corporation, Santa Monica, Calif.
18. Williarns, J. R. and Shelton, S. V., "Gas-Core Reactors for MHD Power Systems," Research on Uranium Plasmas and Their Technological Application. SP-236, 1971, NASA, Washington, D. C., pp. 343-349. 


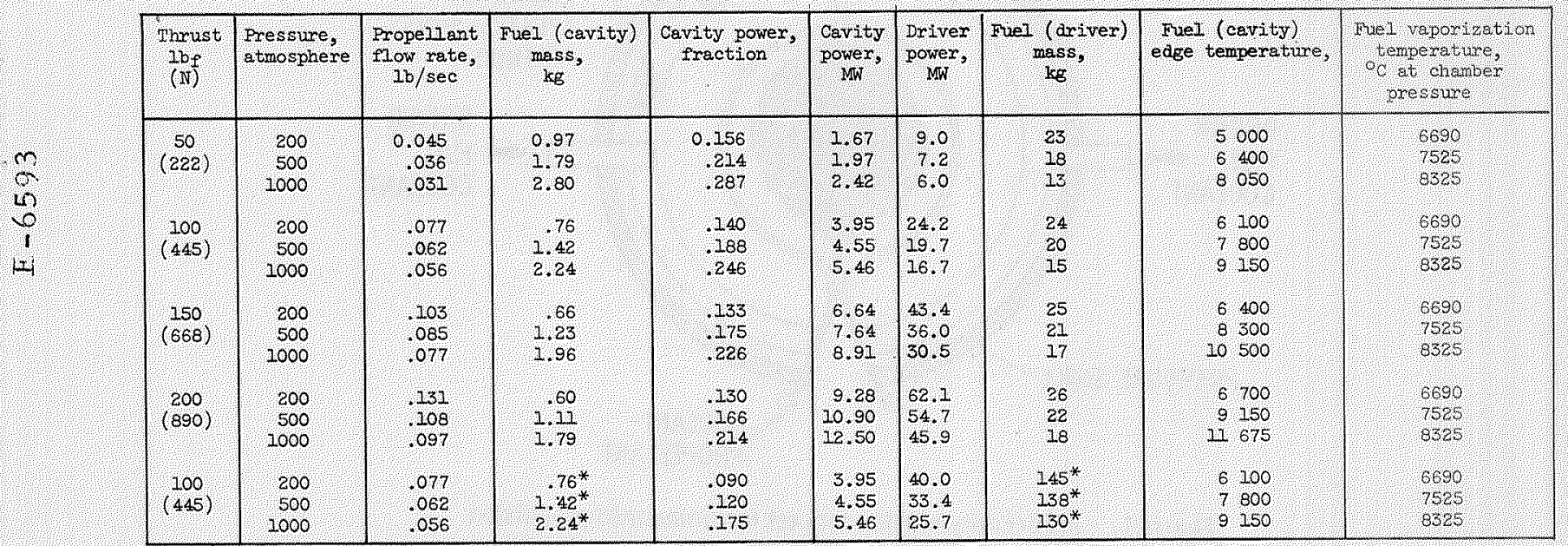

* Fuel was 2350 , ahl others fuel was $233 \mathrm{U}$.

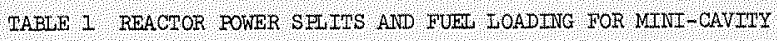

\begin{tabular}{|c|c|c|c|c|c|c|c|c|c|}
\hline \multirow{2}{*}{$\begin{array}{l}\text { Throust } \\
\text { (ib) }\end{array}$} & \multirow[t]{2}{*}{$\begin{array}{l}\text { Pressure, } \\
\text { etmosphere }\end{array}$} & \multirow{2}{*}{$\begin{array}{l}\text { Specific } \\
\text { impulse, }\end{array}$} & \multirow{2}{*}{$\begin{array}{c}\text { prope Juant } \\
\text { tow rate } \\
1 \mathrm{~b} / \mathrm{sec}\end{array}$} & \multirow{2}{*}{$\begin{array}{l}\text { Driver } \\
\text { power, } \\
\text { Mw }\end{array}$} & \multirow{2}{*}{$\begin{array}{l}\text { Reactor } \\
\text { weight, } \\
\text { lb }\end{array}$} & \multirow{2}{*}{$\begin{array}{l}\text { Pressure } \\
\text { shelit weight, } \\
\text { ib }\end{array}$} & \multirow{2}{*}{$\begin{array}{l}\text { Radiator } \\
\text { weight, } \\
\text { Ib }\end{array}$} & \multicolumn{2}{|c|}{$\begin{array}{l}\text { Total polrer } \\
\text { plant weisht }\end{array}$} \\
\hline & & & & & & & & 18 & 46 \\
\hline$(222)$ & $\begin{array}{l}200 \\
500 \\
1000\end{array}$ & $\begin{array}{r}1,00 \\
1375 \\
1600\end{array}$ & $\begin{array}{l}0.045 \\
.036 \\
.031\end{array}$ & $\begin{array}{l}9.0 \\
7,2 \\
6.0\end{array}$ & $\begin{array}{l}4800 \\
4800 \\
4800\end{array}$ & $\begin{array}{l}800 \\
1.860 \\
4000\end{array}$ & $\begin{array}{l}1350 \\
5 \quad 780 \\
7 \quad 880\end{array}$ & $\begin{array}{l}1.0,150 \\
12.610 \\
16880\end{array}$ & $\begin{array}{l}4615 \\
7,670\end{array}$ \\
\hline$(100)$ & $\begin{array}{l}200 \\
500 \\
1000\end{array}$ & $\begin{array}{r}300 \\
-600 \\
-8000\end{array}$ & $\begin{array}{l}.077 \\
.062 \\
.056\end{array}$ & $\begin{array}{l}24.2 \\
19.7 \\
16.7\end{array}$ & $\begin{array}{l}4800 \\
4800 \\
4800\end{array}$ & $\begin{array}{r}800 \\
1860 \\
4000\end{array}$ & $\begin{array}{l}\frac{11}{15} 700 \\
22 \quad 200\end{array}$ & $\begin{array}{l}17500 \\
22680 \\
31,200\end{array}$ & $\begin{array}{l}1.950 \\
10,300\end{array}$ \\
\hline$\left(\begin{array}{l}250 \\
(668)\end{array}\right.$ & $\begin{array}{l}200 \\
500 \\
1000\end{array}$ & $\begin{array}{l}1460 \\
1770 \\
1960\end{array}$ & $\begin{array}{l}.03 \\
.085 \\
.077\end{array}$ & $\begin{array}{l}43.4 \\
36.0 \\
30.5\end{array}$ & $\begin{array}{l}4800 \\
4800 \\
4800\end{array}$ & $\begin{array}{l}8000 \\
4060\end{array}$ & $\begin{array}{l}21000 \\
28900 \\
40 \quad 590\end{array}$ & $\begin{array}{l}26800 \\
35 \\
49 \quad 590\end{array}$ & 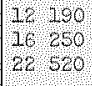 \\
\hline$(890)$ & $\begin{array}{r}200 \\
500 \\
1000\end{array}$ & $\begin{array}{l}1530 \\
1850 \\
2060\end{array}$ & $\begin{array}{r}.131 \\
.098\end{array}$ & $\begin{array}{l}62.7 \\
54.7 \\
4.9\end{array}$ & $\begin{array}{l}4800 \\
4800 \\
4800\end{array}$ & $\begin{array}{l}800 \\
1850 \\
4000\end{array}$ & $\begin{array}{ll}30 & 060 \\
63 & 900 \\
61 & 100\end{array}$ & $\begin{array}{l}35 \\
50 \\
70 \\
70 \\
100\end{array}$ & 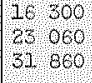 \\
\hline$(400)$ & $\begin{array}{l}200 \\
500 \\
1000\end{array}$ & $\begin{array}{l}-300 \\
1600 \\
2800\end{array}$ & $\begin{array}{l}.099 \\
.062 \\
.056\end{array}$ & $\begin{array}{l}40.0 \\
35.4 \\
25.7\end{array}$ & $\begin{array}{l}5100 \\
5100 \\
5100\end{array}$ & $\begin{array}{r}800 \\
1860 \\
4000\end{array}$ & $\begin{array}{l}19350 \\
26 \\
34 \\
34200\end{array}$ & $\begin{array}{l}25,450 \\
33.980 \\
43 \quad 500\end{array}$ & $\begin{array}{lll}1 & 5 & 0 \\
16 & 450 \\
19 & 770\end{array}$ \\
\hline
\end{tabular}

TABLE 2 POWERTIANT CHARACTERISTICS AND WEIGFT 


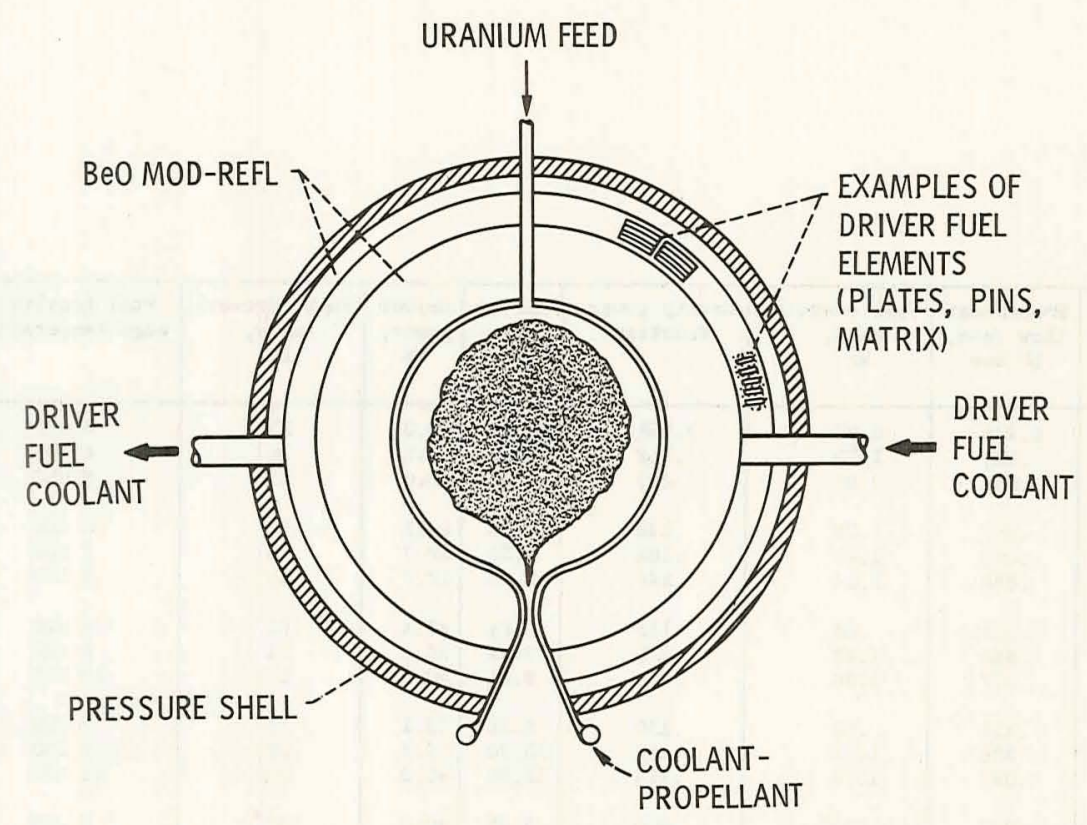

Figure 1. - Mini-cavity reactor concept for unmanned propulsion reactor diameter 1.22 meters; cavity diameter 0.61 meters.

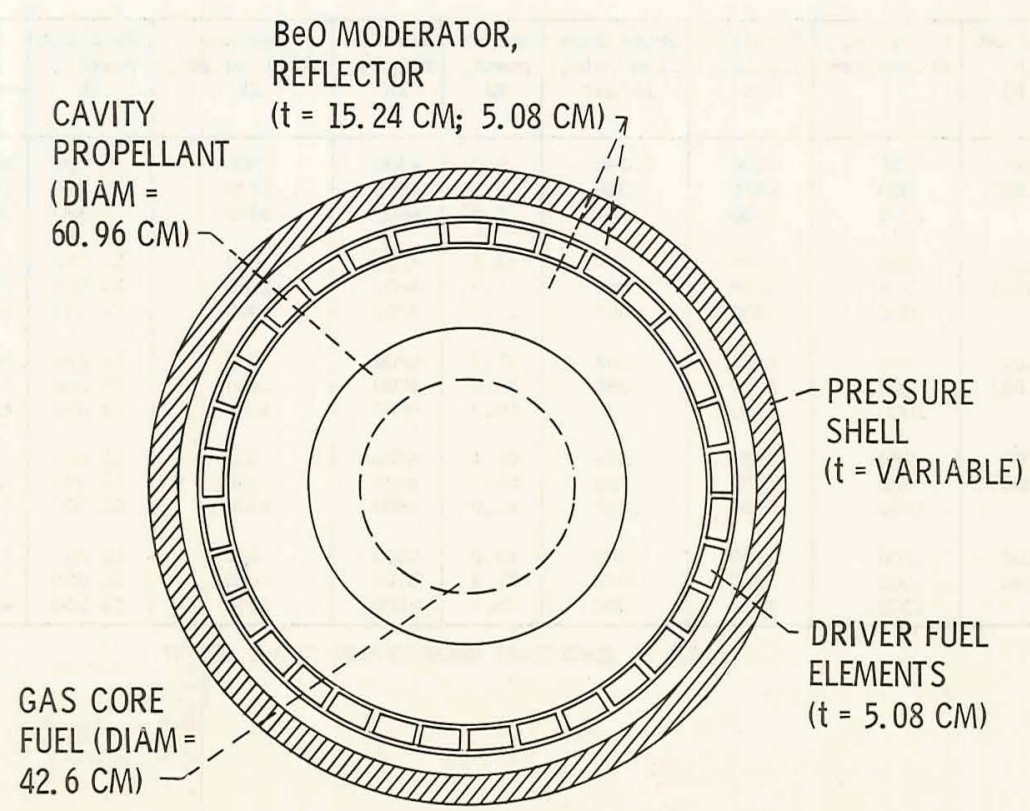

Figure 2. - Spherical calculation model of mini-cavity reactor. 


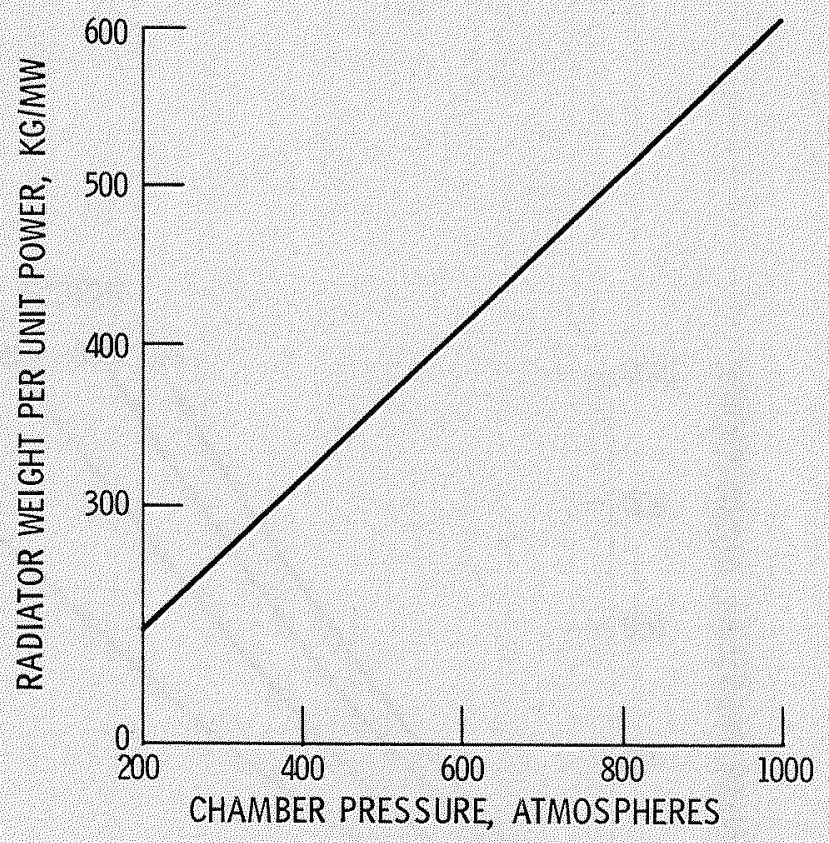

Figure 3. - Radiator weight for mini cavity $\mathrm{T}_{\text {radiator }} 1000^{\circ} \mathrm{C}$, helium coolant.

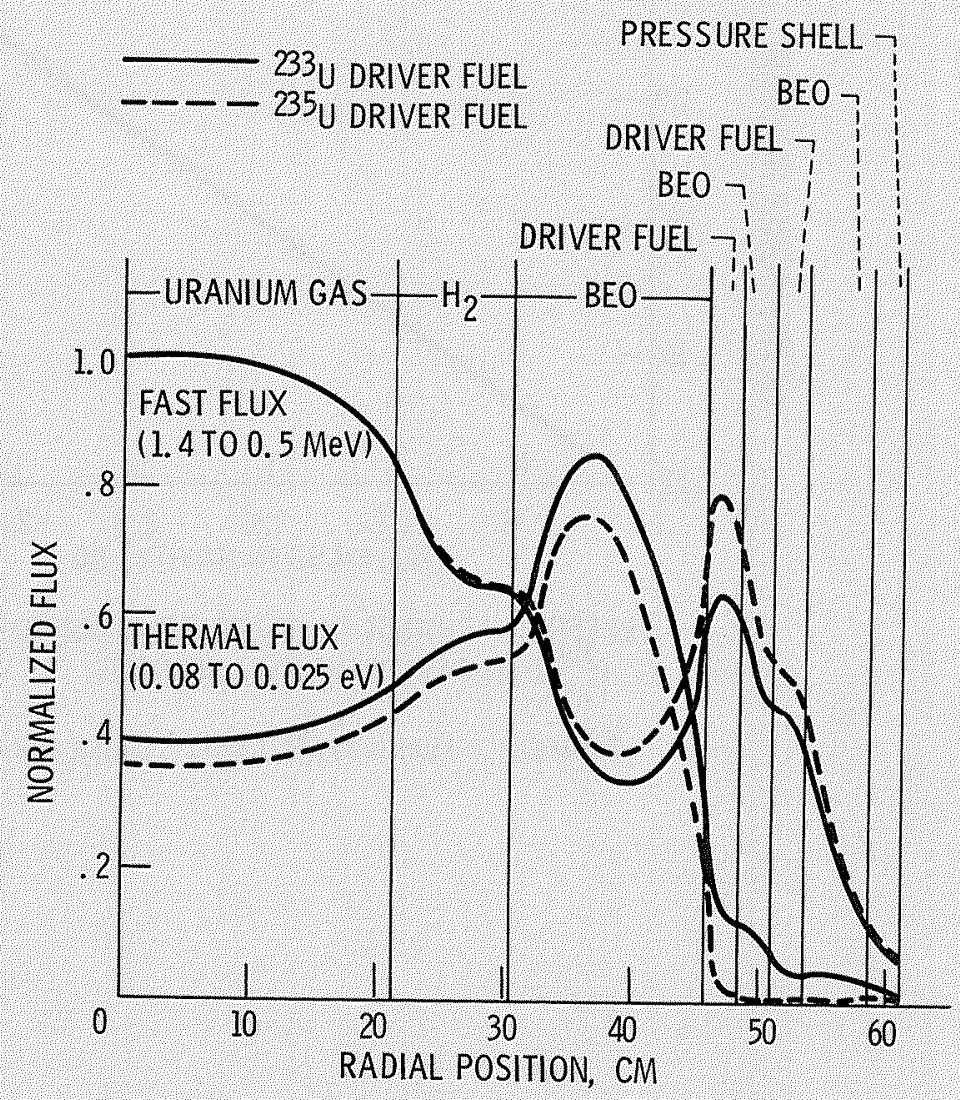

Figure 4. - Neutron flux for mini cavity reactor. 
THRUST, NEWTONS
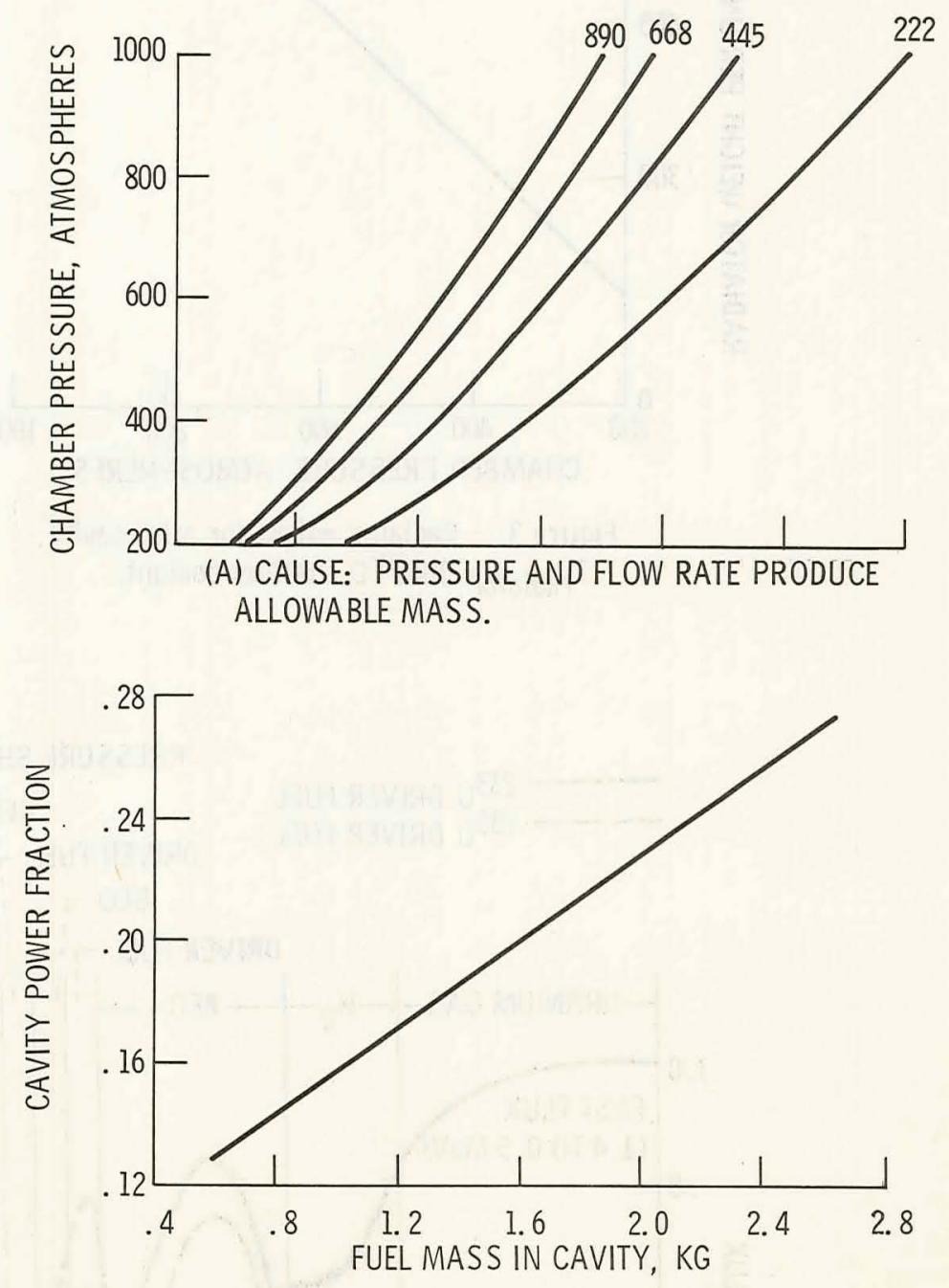

(B) EFFECT: CHANGE IN POWER SPLIT DUE TO MASS (233 U) IN CAVITY THRUST, NEWTONS.

Figure 5. - Fuel mass in cavity - cause and effect. 


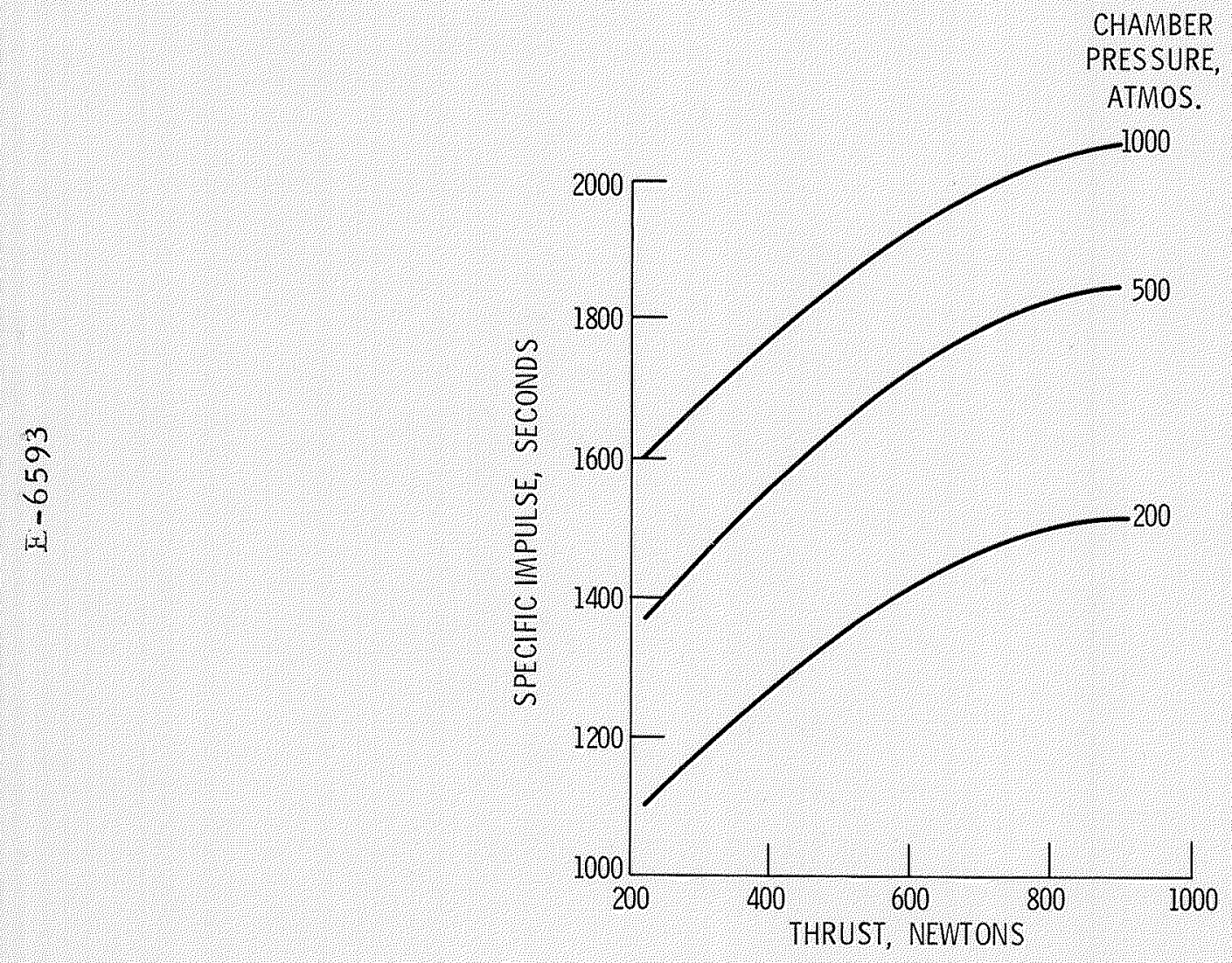

Figure 6. - Cavity specific impulse.

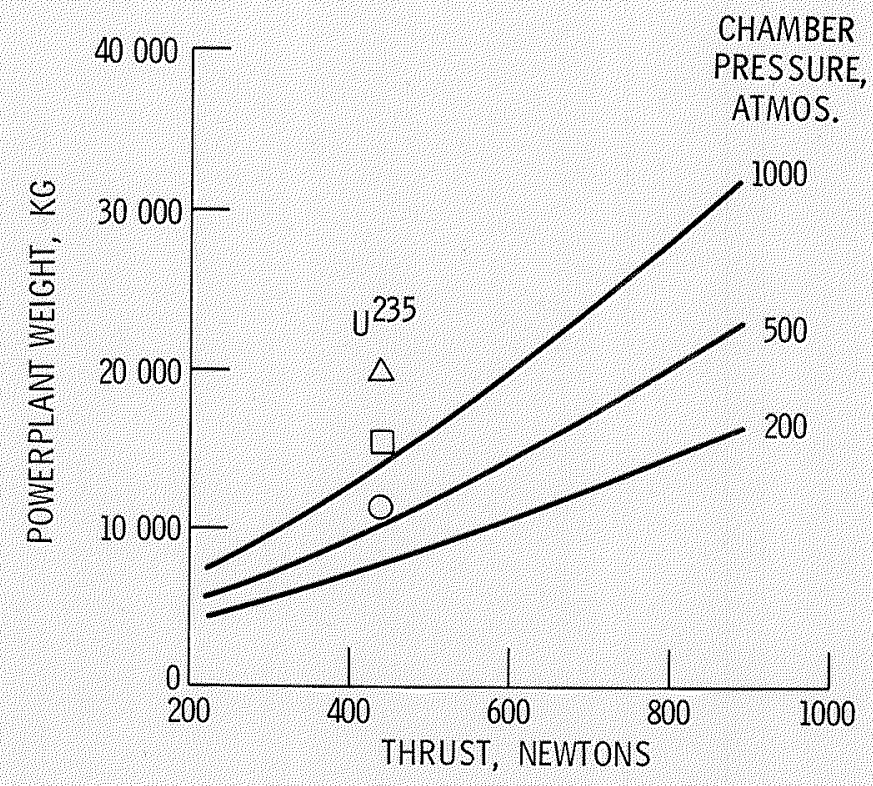

Figure 7. - Mini-cavity powerplant weights (uranium-233 fuel). 